\title{
Opportunities and challenges in lung cancer screening implementation: a narrative review
}

\author{
Eduardo R. Nunez ${ }^{1}$, Katrina A. Steiling ${ }^{1}$, Virginia R. Litle ${ }^{2}$ \\ ${ }^{1}$ The Pulmonary Center, Boston University School of Medicine, Boston, MA, USA; ${ }^{2}$ Division of Thoracic Surgery, Boston University School of \\ Medicine, Boston, MA, USA \\ Contributions: (I) Conception and design: All authors; (II) Administrative support: None; (III) Provision of study materials or patients: None; (IV) \\ Collection and assembly of data: All authors; (V) Data analysis and interpretation: All authors; (VI) Manuscript writing: All authors; (VII) Final \\ approval of manuscript: All authors. \\ Correspondence to: Eduardo R. Nunez. The Pulmonary Center, 72 East Concord Street, R304, Boston, MA 02118, USA.
}

Email: Eduardo.Nunez@bmc.org.

\begin{abstract}
The U.S. Preventive Services Task Force and the Centers for Medicare and Medicaid Services (CMS) recommend lung cancer screening (LCS) for high risk current and former smokers. Developing a comprehensive LCS program requires coordinated planning from program conception through implementation and maintenance that address both pragmatic and regulatory matters. In this review article, we discuss the available evidence, guideline recommendations, and practical considerations for implementing a high-quality LCS program. Key factors in the initial planning phase include engagement of stakeholders with a particular focus on support from providers, patients and healthcare organizations. Additionally, it is important to consider the infrastructure and program design that will best serve local needs, and implement mandatory components such as a data registry and smoking cessation. We also discuss the implementation phase including strategies for optimizing the eligible patient population to be screened as well as the processes of shared decision making (SDM), standardization of screening results and communication of findings to patients. Once patients have been screened, maintenance of a successful LCS program requires iterative multidisciplinary reviews of key quality metrics and establishing systematic mechanisms to track evaluation, minimizing loss to follow-up. We also review other recommended components that contribute to maintaining a high-quality screening program such as a clinical screening coordinator, patient navigator, and tools to improve the uptake of and adherence to LCS.
\end{abstract}

Keywords: Lung cancer screening (LCS); lung cancer; implementation

Received: 22 September 2020; Accepted: 19 October 2020; Published online: 10 November 2020.

doi: $10.21037 /$ ccts-20-160

View this article at: http://dx.doi.org/10.21037/ccts-20-160

\section{Introduction}

Lung cancer remains the leading cause of cancer death in both men and women with an estimated 1.8 million deaths annually worldwide. Both the National Lung Screening Trial (NLST) and NELSON (NederlandsLeuvens Longkanker Screenings Onderzoek) trial showed that lung cancer screening (LCS) with low-dose computed tomography (LDCT) resulted in a $20-24 \%$ reduction in mortality from lung cancer (1,2). In 2013 the U.S. Preventive Services Task Force endorsed LCS for high- risk individuals as a grade $\mathrm{B}$ recommendation, and the Centers for Medicare and Medicaid Services (CMS) started providing coverage for LCS in 2015 (3).

Currently there are approximately 7.6 million Americans that would be eligible for LCS but only an estimated 4-14\% have actually undergone any LCS exam (4-6). Barriers to adherence exist at the patient-level (e.g., reduced access to preventive healthcare among smokers), provider-level (e.g., insufficient knowledge of LCS and pulmonary nodule evaluation), and system-level (e.g., insufficient resources 

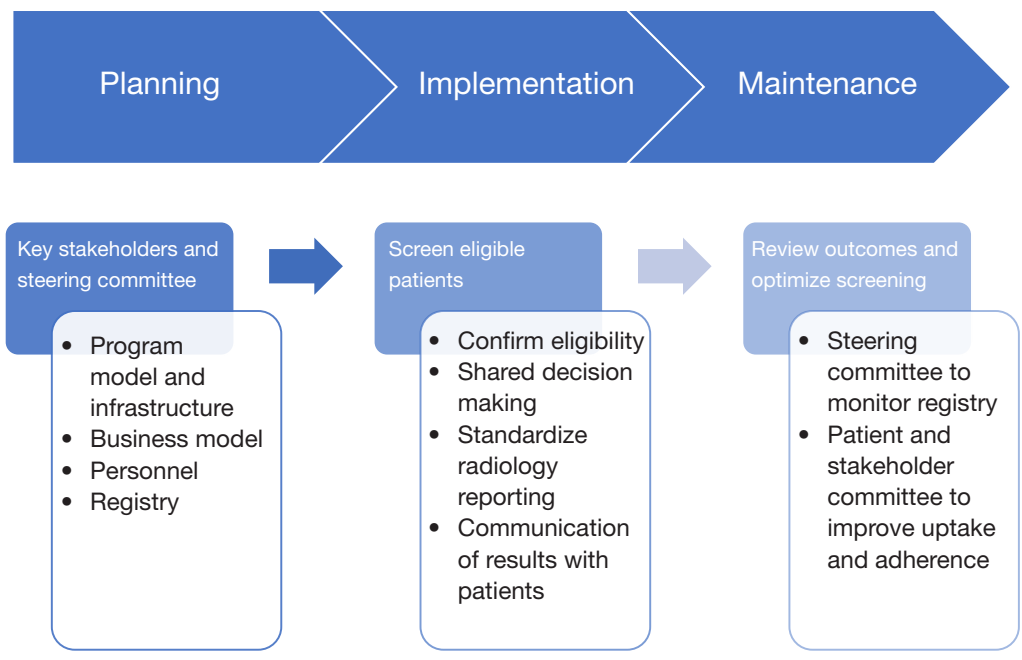

Figure 1 Lung cancer screening implementation process.

to track and ensure appropriate evaluation) (7-10). A multifaceted approach is required to address barriers in screening, with development of a screening program being a critical component to minimize disparities in lung cancer care.

Implementation of high-quality LCS requires careful consideration of the available support and infrastructure. Many centers have already established LCS programs which provides the opportunity to learn from their experiences. As such, professional society guidelines exist that offer concise outlines of expert panel recommendations $(8,11,12)$. The objective of this review is to expand on the current available evidence and guideline recommendations to provide a detailed and evidence-based approach to implementing a comprehensive LCS program. We present the following article in accordance with the Narrative Review reporting checklist (available at https://ccts.amegroups.com/article/ view/10.21037/ccts-20-160/rc).

\section{Methods}

We searched the PubMed database for articles on LCS and implementation of LCS programs. The Medical Subject Headings (MeSH) search terms used were "lung cancer screening" [MeSH]; "lung cancer screening implementation" $[\mathrm{MeSH}]$; "lung cancer screening program" $[\mathrm{MeSH}]$; "lung cancer screening implementation clinical guidelines" [MeSH]; "lung cancer screening program implementation" $[\mathrm{MeSH}]$; Non-MeSH search terms used were lung cancer screening, lung cancer screening program implementation, lung cancer screening clinical guidelines, CMS requirements for lung cancer screening. Only articles including human subjects and those published from 2010 to the present were included. Articles in languages other than English were excluded. Electronically available publications and all study designs including qualitative, quantitative and reviews were considered. Guidelines and resources from international organizations and CMS were used where appropriate. This search was last updated on October 2, 2020.

\section{The planning phase}

The initial step in developing a high-quality LCS program is the planning phase. The planning phase encompasses engagement of key stakeholders, evaluation and selection of the optimal program model and infrastructure, delineation of a strategy for data collection and registry submission, and personnel considerations (Figure 1). Current guidelines suggest giving significant weight to the consideration of local factors such as the hospital system, patient population, community structure and workflow when planning for a LCS program $(8,11)$.

\section{Engaging key stakebolders}

Starting an effective LCS program requires involvement of the key stakeholders. These are individuals that will be affected by the implementation of LCS, and whose interests and expertise should be represented from the 


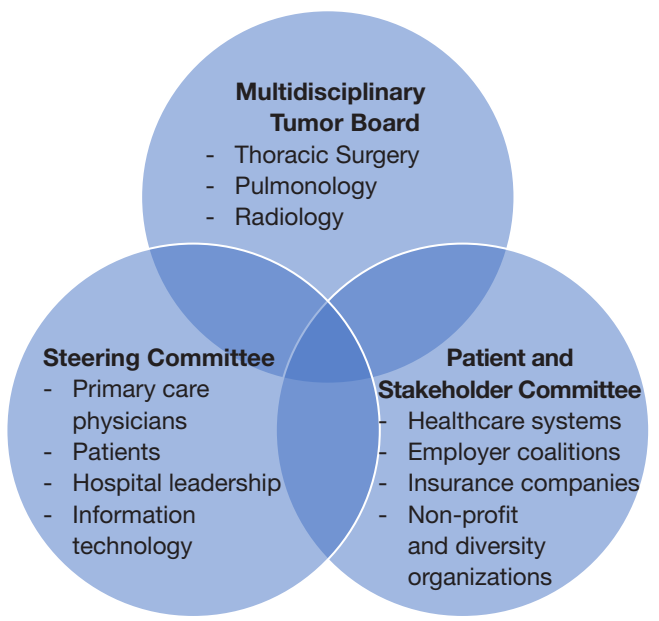

Figure 2 Key stakeholders and members of each committee involved in lung cancer screening implementation with potential for overlap.

outset. Stakeholders can include Primary Care Physicians (PCPs), thoracic surgeons, pulmonologists, interventional radiologists, oncologists, support staff and importantly, patients. One approach to ensuring involvement of these key stakeholders from program conception through program maintenance is by establishing a multi-disciplinary governance committee, or steering committee (13) (Figure 2). At some institutions, the steering committee can leverage the available infrastructure of an existing multidisciplinary pulmonary tumor board, while other institutions have a separate governance committee. The goal of this committee is to ensure that the interests and expertise of the key stakeholders are heard and represented throughout the implementation process, and for members to identify leaders and effective tools for the new LCS program.

Beyond engaging key stakeholders in the program, establishing support from local PCPs is foundational for an effective LCS program $(14,15)$. PCPs should be specifically included during the planning stages of developing a LCS program in order to provide input on local workflow issues and potential barriers to uptake or adherence. Previous studies have suggested that up to $44 \%$ of PCPs are unsure or not planning to screen their patients for lung cancer. Barriers to screening that were frequently cited included uncertainty about the clinical benefits of screening, uncertainly about guidelines recommendations, concern about lack of infrastructure support and lack of time to discuss LCS with patients $(16,17)$. Failure to engage PCPs from the beginning stages may result in low uptake of LCS and poor adherence to follow-up recommendations. Facilities that have implemented LCS programs described the importance of obtaining PCP "buy-in" through educational sessions, feedback of local outcomes, and assigning clear responsibility for nodule evaluation $(14,18,19)$. In addition, educational programs for health care providers can improve adoption of LCS into routine clinical practice by helping providers to appropriately identify atrisk patients and manage screening results.

In addition to allying with PCPs during the planning phase, it is equally important to engage the local healthcare system leadership and develop a business model. There are several costs to establishing LCS including personnel, equipment and information technology (IT) which should be considered in an initial business model $(8,14)$. Furthermore, engagement of local leadership can facilitate the initial financial support that is necessary to launch a comprehensive and high-quality LCS program.

Beyond clinicians and administration, it is paramount to include patient and community representation at the planning stages of an LCS program. This step is critical as only $58 \%$ of Veterans and $12 \%$ of non-Veteran populations have reported a prior discussion with a provider about LCS $(20,21)$. Community outreach and marketing can help to raise awareness about LCS for both patients and clinicians (22). Some marketing strategies proven to be effective for LCS programs include hosting community screening days, direct consumer advertisements, educational websites and telephone access lines to facilitate self-referrals $(22,23)$. Development of websites should be conscientious of presenting information that is balanced with regards to the benefits and harms of LCS, as a study evaluating LCS websites found that benefits were discussed twice as frequently as harms (24).

\section{Program model and infrastructure}

The infrastructure and appropriate program model for each LCS program depends on the available resources and practice setting. Most LCS programs fit into one of three general types of models: centralized, decentralized or hybrid (11).

A decentralized LCS program is a program which allows the ordering provider, commonly PCPs, to perform the key program functions. This includes determining LCS eligibility, performing an in-person shared decision making (SDM) discussion with the patient, ordering the appropriate 
exam, communicating the results of the test and managing the follow-up evaluation whether it would be surveillance CT chest, positron emission tomography (PET), or an invasive procedure. Additionally, given the requirements for establishing LCS programs, the ordering provider would also have to be responsible for smoking cessation and tracking the results in a registry.

By contrast, in centralized programs the ordering provider may determine initial LCS eligibility but then defers key program functions to program personnel. For example, a PCP or pulmonologist may identify a patient as being appropriate for LCS and have the initial SDM discussion with the patient. If the patient is agreeable to entering screening, the ordering provider would place a referral to LCS. The LCS screening coordinator would confirm that the patient meets LCS eligibility criteria and verify that SDM took place. The screening coordinator would then order the appropriate LDCT and follow-up to ensure adherence to the test as well as the results. For highrisk findings, centralized screening programs often have a multidisciplinary tumor board designed to discuss complex cases and results would be communicated to the patient through an in-person visit to one of the member specialties of the multidisciplinary tumor board. The LCS program infrastructure would then be responsible of monitoring adherence to recommendations and maintaining updates to the registry.

A hybrid model for LCS combines the elements of centralized and decentralized to meet the needs of its patients in the context of the local healthcare system. In a hybrid model, ordering providers, usually PCPs or pulmonologists, are responsible for identifying patients eligible for LCS, performing SDM, ordering the LDCT and managing the findings of screening. Unlike decentralized programs in which the ordering providers are responsible for both low-risk and high-risk findings, in a hybrid model the LCS program may have an infrastructure which supports ordering providers in management of high-risk findings. For example, some programs have a multidisciplinary tumor board that discusses all high-risk cases and communicates recommended next steps to the ordering provider automatically without being consulted. This key function ensures that important results don't get lost to follow-up and 'fall through the cracks'. In addition, the LCS program supports patients and providers by helping to manage the registry and tracking evaluation results.

Current guidelines do not recommend any particular model over another. There is no evidence superiority of any particular model type and experts recognize that the most important consideration when selecting a model is the resources and context of the LCS program, with there being no 'one size fits all' recommendation (25).

\section{Registry}

The CMS requires the use of a structured reporting system and collection of specific data elements as part of a registry. This is a requirement for LCS programs in order to receive reimbursement from CMS. Registries facilitate collection and tracking of data in a systematic and reproducible manner. For LCS programs, maintenance of a local registry can also help support the monitoring of recommended follow-up including whether patients have been scheduled or are overdue for a recommended evaluation (26). Planning regarding IT infrastructure for the LCS program is an important consideration to ensure timely and accurate collection of data required for registry submission and reimbursement.

Registry data points include patient identification and demographics, smoking history, LCS scan information and results, recommended follow-up evaluation, and the results of any additional testing related to LCS results including pathology and staging information (27). Other data points that may be helpful to collect at the local level to augment screening adherence include contact information for patients, imaging characteristics of the nodules detected, patient navigation notes, and upcoming evaluations. Many programs facilitate data entry into registries via the EMR which can often be used to automatically submit data to the American College of Radiology (ACR) Lung Cancer Screening Registry or other registries (12). Alternatively, a manual tracking system could be used, although this limits the ability to scale the program as more patients are screened. Regardless of the method of data collection and entry, the registry should be maintained and updated regularly by a designated individual(s) to assure the data integrity and to facilitate clinical care.

\section{Personnel}

Given the complexity of coordinating the varied aspects of a high-quality LCS program, it is important to have a lead clinician who monitors, guides and implements improvements for the LCS program. In addition to a lead clinician, many sites designate either a nurse navigator or 
mid-level provider to the role of screening coordinator. The role of the screening coordinator is to communicate with patients and referring providers, and coordinate follow-up testing (28). Other sites delegate this role to a pulmonologist or another physician, such as a PCP with interest in LCS. The screening coordinator should have ready access to the clinical director of LCS as well as ancillary support staff or multidisciplinary tumor board if present.

Another type of personnel that could be included as part of the LCS program are patient navigators. Patient navigators are team members that are culturally and linguistically equipped to assist patients overcome barriers to care (29). Patient navigators have previously been shown in other cancer screening programs to help improve adherence in low-income populations and racial/ ethnic minorities $(30,31)$. These benefits are also likely to be extended to LCS, as early studies have demonstrated a higher rate of LCS uptake with the use of a patient navigator $(32,33)$.

A final personnel consideration is ensuring adequate local radiology expertise in order to consistently and appropriately interpret LCS CT scans. Some programs accomplish this though a dedicated group of chest radiologists who are responsible for interpreting LCS exams. Other programs designate this responsibility to radiology working group which is responsible for achieving consistency in reporting within the radiology department. CMS requires that reading radiologists have been trained in radiation safety, be radiology board eligible, have interpreted at least 300 chest CTs in the past 3 years and obtain screening with LDCT in an LCS eligible radiology imaging facility (34).

\section{Implementation phase}

The next step in setting up an LCS program is implementation. This multifaceted step includes identification of eligible patients, SDM, smoking cessation counseling, performing and reporting the LCS exam, and communication of the screening results to patients and referring physicians.

\section{Identification of eligible patients}

Implementation of a comprehensive LCS program starts with ensuring that screening is provided to the appropriate individuals. The first step towards this end is to determine which of the several published guidelines for LCS eligibility should be used within the program. Guidelines include those from the United States Preventive Services Task Force (USPSTF) (35), the CMS (34), and the National Comprehensive Cancer Network (NCCN) (36). All guidelines support the screening of patients aged 55-74 that are current smokers or former smokers that quit within the last 15 years, with at least a 30 pack-years cumulative exposure. The USPSTF has drafted recommendations to update their eligibility criteria to include age ranges $50-80$, and reduce the minimum pack-years to 20 (37). This guideline pertains to patients with private insurances under the Affordable Care Act. CMS permits screening until age 77, and pertains to patients with Medicare and Medicaid. In addition to the high-risk group covered under USPSTF and CMS eligibility criteria, the NCCN extends eligibility to individuals aged 50 or older with at least 20 pack years and additional risk factors that increase the risk of lung cancer at least $1.3 \%$. Reimbursement for this second group of potentially eligible patients varies by insurer.

Not only should the population being screened be at higher risk of lung cancer, but patients should also be healthy enough to benefit from screening (38). Even though an individual may be eligible for LCS based on their age and smoking history, it may be inappropriate to undergo screening if they have many comorbidities or short life expectancy, resulting in more harms than benefits from LCS (39). For example, patients eligible for LCS who had a Charlson Comorbidity Index of $\geq 2$ that underwent surgery for stage I lung cancer had worse 5-year survival, suggesting that competing causes of death played a role and reduced the potential benefit of screening for decreasing overall mortality (40). While there is currently no agreed upon method to determine which combination of co-morbidities should preclude screening, the use of decision aids can help in this SDM process (41-44).

Historically clinical care providers have been tasked with identifying patients eligible for screening exams, including LCS. More recently, the electronic medical record (EMR) has shown increasing utility as a tool for identifying potentially eligible individuals. Useful EMR tools include pack-year smoking history which are entered by clinicians, clinical reminders such as health maintenance alerts for potentially eligible individuals, and order sets for LCS that confirm patient eligibility $(45,46)$. Integration of the EMR into the LCS is dependent on local factors such as the specific EMR in use, and the availability of IT support for implementation of tools specific to LCS. 
In addition to utilizing the EMR to identify individuals eligible for LCS, human review of LCS eligibility remains a required step. One study showed that the EMR alone was approximately $95 \%$ discordant with clinical history obtained during a SDM visit and is not sufficiently accurate to deem eligibility (46). Furthermore, CMS requires clinician documentation of eligibility criteria for patients undergoing LCS. While a potential barrier to LCS uptake, this essential step further provides the ordering provider an opportunity to review not only eligibility, but also potential comorbidities or goals of care that might limit the benefit of screening. Alternatively, some programs designate the screening program coordinator to confirm patient eligibility either through direct communication (telephone or inperson) with the patient or through chart review $(14,47)$.

\section{Shared decision making}

CMS requires an SDM visit to discuss the benefits and harms of LCS $(48,49)$. The goal of SDM is for patients and providers to discuss and come to a consensus about how the potential benefits and harms of screening affect an individual's decision to undergo screening or not. Often, PCPs are tasked with conducting the SDM, as patients may benefit from having an already established rapport. However, studies have suggested that PCPs struggle to find sufficient time in brief follow-up visits to perform SDM and medically manage several complex comorbidities $(17,50)$. Pulmonologists also frequently perform SDM for LCS with their patients as they may already be under pulmonary medicine care for chronic obstructive pulmonary disease (COPD) or an incidental lung nodule in a patient who would otherwise meet LCS eligibility criteria. While prior studies suggest that pulmonologists may be more comfortable identifying appropriate patients for LCS and discussing follow-up recommendations with patients, barriers include insufficient infrastructure to coordinate effective and timely follow-up (51,52). In other programs, LCS coordinators perform SDM (51). Importantly, CMS requires that SDM occurs during an in-person visit with a clinical provider (physician, physician assistant, nurse practitioner or clinical nurse specialist) which may be a limitation that may need to be re-addressed in the current Coronavirus-19 climate focused on improving social distancing (48).

\section{Smoking cessation counseling}

CMS requires smoking cessation counseling as part of a
LCS program to receive reimbursement for screening, and is also strongly recommended as a required component in LCS implementation guidelines $(11,48,49,53)$. Smoking is strongly associated with lung cancer mortality, and smoking cessation is key to reducing preventable deaths from lung cancer. Prior studies have shown that there is no difference in smoking cessation or relapse relates between those undergoing LCS and those who did not undergo screening, suggesting that the act of screening by itself is not enough to motivate individuals towards cessation $(54,55)$. Additionally, patients may have misconceptions that undergoing screening replaces the benefits of smoking cessation (56). However, it has previously been shown that individuals with abnormal LCS results were more likely to quit than those with normal results, highlighting that LCS can serve as a 'teachable moment' and emphasizes that repeated interventions at multiple time points are more likely to be successful in achieving smoking cessation $(57,58)$. Several interventions for smoking cessation in the setting of LCS have proved useful including written materials with links to online resources and telephone hotlines (e.g., 1-800 QUIT-NOW) (59) (Table 1). Other interventions including nicotine replacement therapy (NRT), medications, and in-person therapy have been found to be efficient outside of the LCS programs and are recommended by smoking cessation guidelines (60-62).

\section{The screening process}

Implementation of a comprehensive LCS is dependent on standardization of the reported results and tracking subsequent evaluation. To address the problem of having varying recommendations for follow-up, the American College of Radiology (ACR) developed Lung CT Screening Reporting \& Data System (Lung-RADS). This system standardizes and streamlines reporting of LCS results and management recommendations (63). LungRADS categorizes LCS results according to the risk of malignancy and includes discrete recommendations for annual screening, interval surveillance, PET scan, or invasive testing for each Lung-RADS category. These discrete recommendations help guide PCPs and health care providers without expertise in thoracic imaging towards specific guideline concordant evaluation options (64). As a quality metric, some LCS programs perform periodic evaluations to determine whether the Lung-RADS system is consistently being applied by different radiologists (8). While not routinely recommended in LCS implementation 
Table 1 List of available smoking cessation interventions and resources that can be implemented along with lung cancer screening

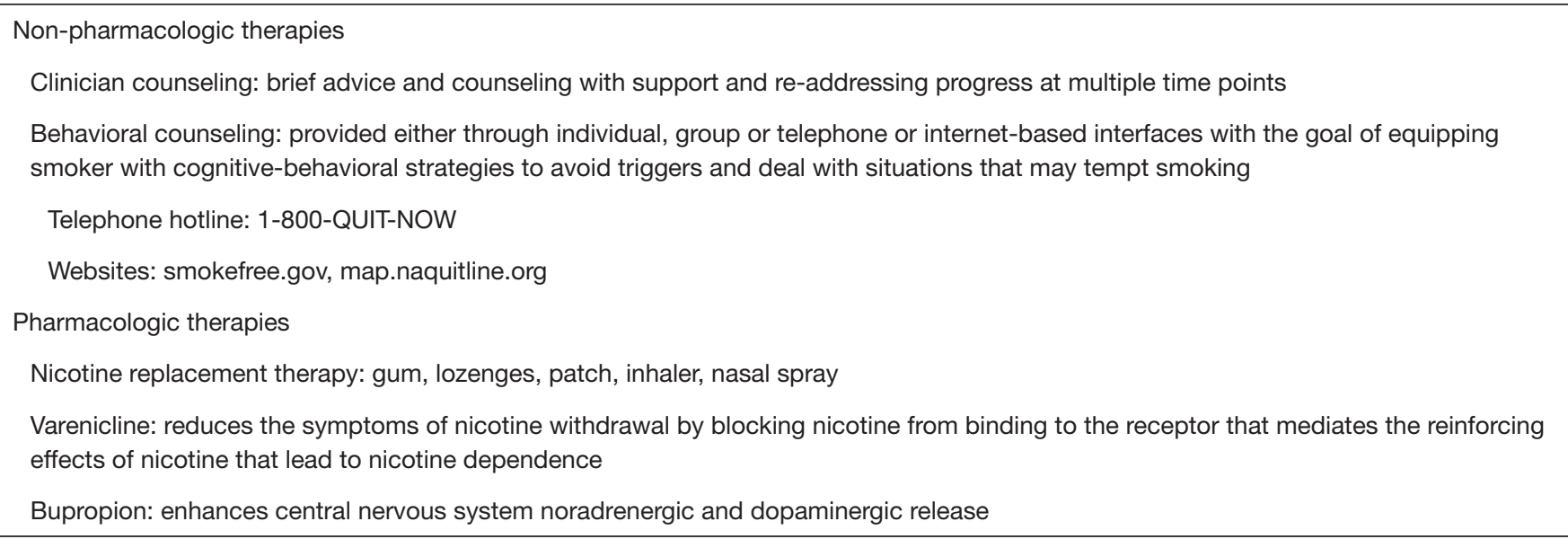

guidelines, this metric may be useful for LCS programs with radiologists that are not specifically trained in thoracic imaging.

Clear delineation of the responsibilities of LCS exam result follow-up and communication of these results is a key factor during the implementation phase. Both PCPs and pulmonologists have cited insufficient infrastructure to manage LCS result tracking and follow-up as a perceived barrier to LCS implementation (17). Prior to implementation of LCS, pulmonologists and thoracic surgeons often guided management of incidental lung nodules given their respective areas of expertise. However, in a large LCS program, this approach has the potential to overwhelm the resources within a department (45). An alternative approach is to risk-stratify LCS exam results based on the Lung-RADS system, and reserve sub-specialty consultation for nodules with a higher risk of malignancy. For example, most lung nodules smaller than $8 \mathrm{~mm}$ have a low probability of malignancy and can be followed with radiographic surveillance $(65,66)$. For larger lung nodules or findings concerning for lung malignancy, both subspecialty evaluation and multi-disciplinary discussion can help ensure that patients receive appropriate and individualized care. This can be accomplished within a multidisciplinary tumor board that includes members from pulmonary, radiology, thoracic surgery and interventional radiology or through multi-disciplinary clinical evaluations $(14,19)$.

\section{Communicating results to patients}

Sensitive communication of LCS findings is paramount, as many patients will have lung nodules, the majority of which are benign. Patients have reported dissatisfaction with communication that is vague about the probability of lung cancer, and also communication containing technical medical jargon (67). Patients have also reported significant distress and anxiety as a result of LCS results, some of which lack diagnostic certainty and require prolonged surveillance (68). Some LCS programs distribute an informational brochure prior to LCS which addresses common questions (69). Many programs communicate normal results to patients via a physical letter mailed to their home address. This process can be facilitated through the use of a registry to generate template letters (51). However, this strategy may only be effective for patients with a completely normal or likely benign LCS. This approach also loses an opportunity for clinicians to connect with patients to re-emphasize the results of quitting smoking. For patients with indeterminate results, some programs suggest supplementing a written letter with a phone call or in-person visit (67). This approach allows patients the opportunity to ask questions and develop better understanding of their results. For patients with moderate to high risk probability of malignancy who may need additional testing or an invasive procedure, communication should occur during an in-person visit.

Beyond lung nodules, LCS can also identify other lung abnormalities or abnormalities outside of the lung that require further evaluation. Examples of significant other findings include thyroid nodules, coronary calcifications, and adrenal nodules. In Lung-RADS reporting system, these are reported as Lung-RADS Category $\mathrm{S}$ which can be added as a modifier to a Lung-RADS 1-4 category. The frequency of identifying significant findings not 
concerning for lung cancer varies significantly by program, and ranges between $3-42 \%$ on baseline screening exams $(70,71)$. Further evidence is needed to develop a systematic approach to manage these findings but at the very minimum the LCS program should have a mechanism in place to ensure that either the PCP or ordering provider is aware of the incidental findings and they feel comfortable with the current infrastructure of their health system to be able to deal with these.

\section{Maintenance phase}

Once LCS is implemented, successful programs will engage in an iterative multidisciplinary review of key quality metrics to ensure high-quality patient care. American Thoracic Society (ATS) and American College of Chest Physicians (ACCP/CHEST) guidelines have proposed several quality metrics to be monitored annually which include (I) appropriate population being screened; ( $\geq 90 \%$ should meet LCS eligibility criteria); (II) adherence to a systematic radiology reporting system, like Lung-RADS ( $\geq 90 \%$ should use structured reporting); (III) nodule evaluation monitoring (tracking how many individuals are adherent to recommended evaluation, how many invasive tests and complications occur; and how many cancers are diagnosed, including their staging); (IV) adherence to smoking cessation interventions including how many patients were offered cessation interventions and participated. Ideally, this data would be collected and monitored through the registry.

Also critical to the success of a LCS program is establishing systematic mechanisms to track evaluation and prevent loss to follow-up. Two mechanisms are development of a healthcare system registry to track data on patients undergoing LCS, which is a CMS requirement, and appointment of a screening program coordinator $(48,72,73)$.

Periodic review of the registry data by the steering committee should occur to ensure the integrity of the registry and if any deficient areas are noted, it should serve as a call to action for to develop a corrective plan. In addition, CMS requires that all LCS programs report the data on all screening performed to a national registry (48). National surveys have found varying levels of readiness and resources for implementing LCS programs, so it is critical to develop mechanisms to collect and track results (74).

Patient and stakeholder committees have also been used to ensure successful maintenance of comprehensive LCS programs (Figure 2). These committees are comprised of key local stakeholders and organizations which can include representatives from participating healthcare systems, employer coalitions, health departments, major insurers, nonprofit and diversity organizations that may have a stake in disparities and cancer outcomes (75). In contrast to steering committees or multidisciplinary tumor boards that may meet every 1-2 weeks to determine timely plans for high-risks findings, patient and stakeholder committees meet approximately quarterly to review screening rates and related disparities to identify factors that may be affecting LCS and recommend strategies that improve efficacy of the local LCS program.

\section{Conclusions}

Currently, there is both sub-optimal uptake to initial LCS and poor adherence to subsequent LCS. It is clear that optimizing the mortality benefits derived from LCS is dependent on high-quality LCS and a comprehensive approach is to key to ensuring success from the initial buy-in phase through to the implementation and maintenance phase that allows for continued quality checks and improvements.

Overall, implementing a high-quality and comprehensive LCS program is dependent on fully utilizing key stakeholders and local infrastructure to develop a program model that will best meet the needs of the patient population. There also needs to be careful considerations for evaluating and performing quality metric reviews to ensure that benefits from LCS are being optimized to reduce mortality from lung cancer in the local community.

\section{Acknowledgments}

Funding: Eduardo R. Nunez is supported by NIH T32 Grant (No. 5T32HL007035).

\section{Footnote}

Provenance and Peer Review: This article was commissioned by the Guest Editor (Sandra Starnes) for the series "Lung Cancer Screening" published in Current Challenges in Thoracic Surgery. The article has undergone peer review.

Reporting Checklist: The authors have completed the Narrative Review reporting checklist. Available at https:// ccts.amegroups.com/article/view/10.21037/ccts-20-160/rc

Conflicts of Interest: All authors have completed the 
ICMJE uniform disclosure form (available at https://ccts. amegroups.com/article/view/10.21037/ccts-20-160/coif). The series "Lung Cancer Screening" was commissioned by the editorial office without any funding or sponsorship. The authors have no other conflicts of interest to declare.

Ethical Statement: The authors are accountable for all aspects of the work in ensuring that questions related to the accuracy or integrity of any part of the work are appropriately investigated and resolved.

Open Access Statement: This is an Open Access article distributed in accordance with the Creative Commons Attribution-NonCommercial-NoDerivs 4.0 International License (CC BY-NC-ND 4.0), which permits the noncommercial replication and distribution of the article with the strict proviso that no changes or edits are made and the original work is properly cited (including links to both the formal publication through the relevant DOI and the license). See: https://creativecommons.org/licenses/by-nc-nd/4.0/.

\section{References}

1. Aberle DR, Adams AM, Berg CD, et al. Reduced lungcancer mortality with low-dose computed tomographic screening. N Engl J Med 2011;365:395-409.

2. de Koning HJ, van der Aalst CM, de Jong PA, et al. Reduced Lung-Cancer Mortality with Volume CT Screening in a Randomized Trial. N Engl J Med 2020;382:503-13.

3. Humphrey LL, Deffebach M, Pappas M, et al. Screening for lung cancer with low-dose computed tomography: a systematic review to update the US Preventive services task force recommendation. Ann Intern Med 2013;159:411-20.

4. Zahnd WE, Eberth JM. Lung Cancer Screening Utilization: A Behavioral Risk Factor Surveillance System Analysis. Am J Prev Med 2019;57:250-5.

5. Richards TB, Doria-Rose VP, Soman A, et al. Lung Cancer Screening Inconsistent With U.S. Preventive Services Task Force Recommendations. Am J Prev Med 2019;56:66-73.

6. Okereke IC, Nishi S, Zhou J, et al. Trends in lung cancer screening in the United States, 2016-2017. J Thorac Dis 2019;11:873-81.

7. Raz DJ, Wu GX, Consunji M, et al. Perceptions and Utilization of Lung Cancer Screening Among Primary Care Physicians. J Thorac Oncol 2016;11:1856-62.

8. Iaccarino JM, Clark J, Bolton R, et al. A National Survey of Pulmonologists' Views on Low-Dose Computed Tomography Screening for Lung Cancer. Ann Am Thorac Soc 2015;12:1667-75.

9. Duong DK, Shariff-Marco S, Cheng I, et al. Patient and primary care provider attitudes and adherence towards lung cancer screening at an academic medical center. Prev Med Rep 2017;6:17-22.

10. Steiling K, Loui T, Asokan S, et al. Age, Race, and Income Are Associated With Lower Screening Rates at a Safety Net Hospital. Ann Thorac Surg 2020;109:1544-50.

11. Mazzone PJ, Silvestri GA, Patel S, et al. Screening for Lung Cancer: CHEST Guideline and Expert Panel Report. Chest 2018;153:954-85.

12. Fintelmann FJ, Bernheim A, Digumarthy SR, et al. The 10 Pillars of Lung Cancer Screening: Rationale and Logistics of a Lung Cancer Screening Program. Radiographics 2015;35:1893-908.

13. McKee A, McKee B, Wald C, et al. Rescue Lung, Rescue Life Translating the National Lung Screening Trial Results into Clinical Practice. Oncology Issues 2014:20-9.

14. McKee BJ, McKee AB, Flacke S, et al. Initial experience with a free, high-volume, low-dose CT lung cancer screening program. J Am Coll Radiol 2013;10:586-92.

15. Olazagasti C, Sampat D, Rothman A, et al. Implementing physician education to increase lung cancer screening compliance. J Clin Oncol 2019;37:e18282.

16. Volk RJ, Foxhall LE. Readiness of primary care clinicians to implement lung cancer screening programs. Prev Med Rep 2015;2:717-9.

17. Triplette M, Kross EK, Mann BA, et al. An Assessment of Primary Care and Pulmonary Provider Perspectives on Lung Cancer Screening. Ann Am Thorac Soc 2018;15:69-75.

18. Gesthalter YB, Koppelman E, Bolton R, et al. Evaluations of Implementation at Early-Adopting Lung Cancer Screening Programs: Lessons Learned. Chest 2017;152:70-80.

19. Mazzone $P$. The rationale for, and design of, a lung cancer screening program. Cleve Clin J Med 2012;79:337-45.

20. Chalian H, Khoshpouri P, Iranmanesh AM, et al. Lung cancer screening patient-provider discussion: Where do we stand and what are the associated factors? SAGE Open Med 2019;7:2050312119854265.

21. Kinsinger LS, Anderson C, Kim J, et al. Implementation of Lung Cancer Screening in the Veterans Health Administration. JAMA Intern Med 2017;177:399-406.

22. Goffin JR, Pond GR, Tremblay A, et al. Use of a marketing plan for recruitment to a lung cancer screening 
study. J Clin Oncol 2017;35:1548.

23. Matt Morrill TA. Lung cancer screening works. But how can we increase compliance? 2018. Available online: https://www.advisory.com/research/imaging-performancepartnership/the-reading-room/2018/10/lung-cancer. Accessed 7/31/2020.

24. Clark SD, Reuland DS, Enyioha C, et al. Assessment of Lung Cancer Screening Program Websites. JAMA Intern Med 2020;180:824-30.

25. Hirsch EA, New ML, Brown SL, et al. Impact of a Hybrid Lung Cancer Screening Model on Patient Outcomes and Provider Behavior. Clin Lung Cancer 2020;21:e640-6.

26. Goulart BHL, Ramsey SD. Moving beyond the national lung screening trial: discussing strategies for implementation of lung cancer screening programs. Oncologist 2013;18:941-6.

27. American College of Radiology. Lung cancer screening registry. Available online: http://www.acr.org/QualitySafety/National-Radiology-Data-Registry/Lung-CancerScreening-Registry. Accessed 8-24-2020.

28. Hunnibell LS, Slatore CG, Ballard EA. Foundations for lung nodule management for nurse navigators. Clin J Oncol Nurs 2013;17:525-31.

29. Fowler T, Steakley C, Garcia AR, et al. Reducing disparities in the burden of cancer: the role of patient navigators. PLoS Med 2006;3:e193.

30. Percac-Lima S, Ashburner JM, Zai AH, et al. Patient Navigation for Comprehensive Cancer Screening in High-Risk Patients Using a Population-Based Health Information Technology System: A Randomized Clinical Trial. JAMA Intern Med 2016;176:930-7.

31. Kim K, Choi JS, Choi E, et al. Effects of CommunityBased Health Worker Interventions to Improve Chronic Disease Management and Care Among Vulnerable Populations: A Systematic Review. Am J Public Health 2016;106:e3-e28.

32. Percac-Lima S, Ashburner JM, Rigotti NA, et al. Patient navigation for lung cancer screening among current smokers in community health centers a randomized controlled trial. Cancer Med 2018;7:894-902.

33. Shusted CS, Barta JA, Lake M, et al. The Case for Patient Navigation in Lung Cancer Screening in Vulnerable Populations: A Systematic Review. Popul Health Manag 2019;22:347-61.

34. Jensen TS, Chin J, Ashby L, Hermansen J, Hutter JD. Final National Coverage Determination on Screening for Lung Cancer with Low Dose Computed Tomography (LDCT). Available online: https://www.cms.gov/ medicare-coverage-database/details/nca-decision-memo. aspx? NCAId $=274$

35. Moyer VA. Screening for lung cancer: U.S. Preventive Services Task Force recommendation statement. Ann Intern Med 2014;160:330-8.

36. Wood DE, Kazerooni EA, Baum SL, et al. Lung Cancer Screening, Version 3.2018, NCCN Clinical Practice Guidelines in Oncology. J Natl Compr Canc Netw 2018;16:412-41.

37. Force UPST. Lung Cancer Screening: Draft Recommendation Statement. Jul 07, 2020. Available online: https://www.uspreventiveservicestaskforce. org/uspstf/draft-recommendation/lung-cancerscreening-2020. Accessed 8/24/20.

38. Kovalchik SA, Tammemagi M, Berg CD, et al. Targeting of Low-Dose CT Screening According to the Risk of Lung-Cancer Death. N Engl J Med 2013;369:245-54.

39. Rivera MP, Tanner NT, Silvestri GA, et al. Incorporating Coexisting Chronic Illness into Decisions about Patient Selection for Lung Cancer Screening. An Official American Thoracic Society Research Statement. Am J Respir Crit Care Med 2018;198:e3-e13.

40. Tanner NT, Dai L, Bade BC, et al. Assessing the Generalizability of the National Lung Screening Trial: Comparison of Patients with Stage 1 Disease. Am J Respir Crit Care Med 2017;196:602-8.

41. Pinsky PF, Church TR, Izmirlian G, et al. The National Lung Screening Trial: results stratified by demographics, smoking history, and lung cancer histology. Cancer 2013;119:3976-83.

42. Lau YK, Caverly TJ, Cao P, et al. Evaluation of a Personalized, Web-Based Decision Aid for Lung Cancer Screening. Am J Prev Med 2015;49:e125-9.

43. Crothers K, Kross EK, Reisch LM, et al. Patients' Attitudes Regarding Lung Cancer Screening and Decision Aids. A Survey and Focus Group Study. Ann Am Thorac Soc 2016;13:1992-2001.

44. Volk RJ, Linder SK, Leal VB, et al. Feasibility of a patient decision aid about lung cancer screening with low-dose computed tomography. Prev Med 2014;62:60-3.

45. Federman DG, Kravetz JD, Lerz KA, et al. Implementation of an electronic clinical reminder to improve rates of lung cancer screening. Am J Med 2014;127:813-6.

46. Modin HE, Fathi JT, Gilbert CR, et al. Pack-Year Cigarette Smoking History for Determination of Lung Cancer Screening Eligibility. Comparison of the Electronic Medical Record versus a Shared 
Decision-making Conversation. Ann Am Thorac Soc 2017;14:1320-5.

47. Arenberg D, Kazerooni EA. Setting Up a Lung Cancer Screening Program. J Natl Compr Canc Netw 2012;10:277-85

48. Jensen TS, Chin J, Ashby L, et al. Final National Coverage Determination on Screening for Lung Cancer with Low Dose Computed Tomography (LDCT). In: Centers for Medicare \& Medicaid Services. editor. Available online: https://www.cms.gov/medicare-coverage-database/details/ nca-decision-memo.aspx? NCAId=274. February 5, 2015.

49. Wender R, Fontham ET, Barrera E Jr, et al. AmericanCancer Society lung cancer screening guidelines. CA Cancer J Clin 2013;63:107-17.

50. Melzer AC, Golden SE, Ono SS, et al. "We Just Never Have Enough Time": Clinician Views of Lung Cancer Screening Processes and Implementation. Ann Am Thorac Soc 2020. doi: 10.1513/AnnalsATS.202003-262OC.

51. Wiener RS, Koppelman E, Bolton R, et al. Patient and Clinician Perspectives on Shared Decision-making in Early Adopting Lung Cancer Screening Programs: a Qualitative Study. J Gen Intern Med 2018;33:1035-42.

52. Rajupet S, Doshi D, Wisnivesky JP, et al. Attitudes About Lung Cancer Screening: Primary Care Providers Versus Specialists. Clin Lung Cancer 2017;18:e417-e423.

53. Jaklitsch MT, Jacobson FL, Austin JHM, et al. The American Association for Thoracic Surgery guidelines for lung cancer screening using low-dose computed tomography scans for lung cancer survivors and other highrisk groups. J Thorac Cardiovasc Surg 2012;144:33-8.

54. Slatore CG, Baumann C, Pappas M, et al. Smoking behaviors among patients receiving computed tomography for lung cancer screening. Systematic review in support of the U.S. preventive services task force. Ann Am Thorac Soc 2014;11:619-27.

55. Ashraf H, Saghir Z, Dirksen A, et al. Smoking habits in the randomised Danish Lung Cancer Screening Trial with low-dose CT: final results after a 5-year screening programme. Thorax 2014;69:574.

56. Zeliadt SB, Heffner JL, Sayre G, et al. Attitudes and Perceptions About Smoking Cessation in the Context of Lung Cancer Screening. JAMA Intern Med 2015;175:1530-7.

57. Tammemägi MC, Berg CD, Riley TL, et al. Impact of lung cancer screening results on smoking cessation. J Natl Cancer Inst 2014;106:dju084.

58. Taylor KL, Cox LS, Zincke N, et al. Lung cancer screening as a teachable moment for smoking cessation.
Lung Cancer 2007;56:125-34.

59. Stead LF, Hartmann-Boyce J, Perera R, et al. Telephone counselling for smoking cessation. Cochrane Database Syst Rev 2013;5:CD002850.

60. Verbiest M, Brakema E, van der Kleij R, et al. National guidelines for smoking cessation in primary care: a literature review and evidence analysis. NPJ Prim Care Respir Med 2017;27:2.

61. Barua RS, Rigotti NA, Benowitz NL, et al. 2018 ACC Expert Consensus Decision Pathway on Tobacco Cessation Treatment: A Report of the American College of Cardiology Task Force on Clinical Expert Consensus Documents. J Am Coll Cardiol 2018;72:3332-65.

62. Leone FT, Zhang Y, Evers-Casey S, et al. Initiating Pharmacologic Treatment in Tobacco-Dependent Adults. An Official American Thoracic Society Clinical Practice Guideline. Am J Respir Crit Care Med 2020;202:e5-e31.

63. Lung CT Screening Reporting \& Data System. American College of Radiology Web site. 2014.

64. Woloshin S, Schwartz LM, Dann E, et al. Using radiology reports to encourage evidence-based practice in the evaluation of small, incidentally detected pulmonary nodules. A preliminary study. Ann Am Thorac Soc 2014;11:211-4.

65. Gould MK, Donington J, Lynch WR, et al. Evaluation of individuals with pulmonary nodules: when is it lung cancer? Diagnosis and management of lung cancer, 3rd ed: American College of Chest Physicians evidence-based clinical practice guidelines. Chest 2013;143:e93S-e120S.

66. Horeweg N, van Rosmalen J, Heuvelmans MA, et al. Lung cancer probability in patients with CT-detected pulmonary nodules: a prespecified analysis of data from the NELSON trial of low-dose CT screening. Lancet Oncol 2014;15:1332-41.

67. Wiener RS, Gould MK, Woloshin S, et al. What do you mean, a spot?: A qualitative analysis of patients' reactions to discussions with their physicians about pulmonary nodules. Chest 2013;143:672-7.

68. Slatore CG, Golden SE, Ganzini L, et al. Distress and patient-centered communication among veterans with incidental (not screen-detected) pulmonary nodules. A cohort study. Ann Am Thorac Soc 2015;12:184-92.

69. Sharma A, O'Connor R, Celestino P, et al. Focus Groups and In-depth Interviews to Guide the Development of Lung Cancer Screening Informational Materials. J Cancer Educ 2019;34:712-8.

70. Jacobs PC, Mali WP, Grobbee DE, et al. Prevalence of incidental findings in computed tomographic screening 
of the chest: a systematic review. J Comput Assist Tomogr 2008;32:214-21.

71. Morgan L, Choi H, Reid M, et al. Frequency of Incidental Findings and Subsequent Evaluation in LowDose Computed Tomographic Scans for Lung Cancer Screening. Ann Am Thorac Soc 2017;14:1450-6.

72. Kinsinger LS, Atkins D, Provenzale D, et al. Implementation of a New Screening Recommendation in Health Care: The Veterans Health Administration's Approach to Lung Cancer Screening. Ann Intern Med 2014;161:597-8.

doi: $10.21037 /$ ccts-20-160

Cite this article as: Nunez ER, Steiling KA, Litle VR. Opportunities and challenges in lung cancer screening implementation: a narrative review. Curr Chall Thorac Surg 2023;5:1.
73. Alsamarai S, Yao X, Cain HC, et al. The effect of a lung cancer care coordination program on timeliness of care. Clin Lung Cancer 2013;14:527-34.

74. Tukey MH, Clark JA, Bolton R, et al. Readiness for Implementation of Lung Cancer Screening. A National Survey of Veterans Affairs Pulmonologists. Ann Am Thorac Soc 2016;13:1794-801.

75. Myers RE, DiCarlo M, Romney M, et al. Using a health system learning community strategy to address cancer disparities. Learn Health Syst 2018;2:e10067. 